\title{
Tracheal mites, Acarapis woodi, greatly increase overwinter mortality in colonies of the Japanese honeybee, Apis cerana japonica
}

\author{
Taro MAEdA ${ }^{1}$, Yoshiko SAKAMOTO ${ }^{2}$ \\ ${ }^{1}$ National Institute of Agrobiological Sciences, 1-2 Ohwashi, Tsukuba, Ibaraki 305-0851, Japan \\ ${ }^{2}$ National Institute for Environmental Studies, 16-2 Onogawa, Tsukuba, Ibaraki 305-8506, Japan
}

Received 28 August 2015 - Revised 20 December 2015 - Accepted 3 February 2016

\begin{abstract}
This study evaluated the damage caused by the tracheal mite Acarapis woodi to colonies of the Japanese honeybee Apis cerana japonica, by investigating mite prevalence and colony death of the honeybees during winter. Honeybees of 114 colonies were sampled from October to December to detect mite prevalence. The colony death was monitored up to the end of April. The observed mortality due to mite infestation was compared with data from two previous studies about European honeybees. Under normal conditions in the absence of mites, $21 \%$ of intact colonies died during the winter season. However, once the honeybee colonies were infested with A. woodi, the overwinter mortality was drastically increased. The mortality of Japanese honeybee colonies infested with the tracheal mites was higher than that reported historically in European honeybee colonies infested with the mites. Investigation of colony mortality at the apiary level showed that mortality was significantly higher in miteinfested than non-infested apiaries, but there were no significant differences related to the estimated winter air temperature. These results suggest that tracheal mite infestation seriously increases the overwinter mortality of Japanese honeybees.
\end{abstract}

Asian honeybee / tracheal mite / colony death / overwinter mortality

\section{INTRODUCTION}

The endoparasitic tracheal mite, Acarapis woodi, lives in the tracheal system of the European honeybee Apis mellifera (Wilson et al. 1997) and Asian honeybee A. cerana (Milne 1957; Singh 1957; Kojima et al. 2011). A. woodi sucks the haemolymph from honeybees (Pettis and Wilson 1996) and causes damage to both individuals (Bailey and Lee 1959; Eischen 1987; Liu 1990; Komeili and Ambrose 1991) and colonies (Eischen et al. 1989; Bailey and Ball 1991; Otis and Scottdupree 1992). The most critical damage inflicted by tracheal mites on the honeybee colonies is

Corresponding author: T. Maeda, tarom@affrc.go.jp Manuscript editor: Peter Rosenkranz colony death during winter (Clark 1991; McMullan and Brown 2009; Maeda 2016).

Losses to European honeybee colonies caused by $A$. woodi have been widely reported in many countries since the start of the twentieth century (Phillips 1922; Borchert 1940; Butler 1945; Wilson et al. 1997). Infestation by tracheal mites clearly increases the overwinter mortality of European honeybees (Otis and Scott-dupree 1992). For example, when the mite prevalence (percentage of infested bees in a colony) is more than $60 \%$, overwinter mortality in cool winter climates has been reported to reach 70-90\% (Bailey 1958, 1961; Bailey and Lee 1959; Furgala et al. 1989; Otis and Scott-dupree 1992).

Just as with European honeybees, two subspecies of Asian honeybees, the Indian honeybee A. cerana indica and Japanese honeybee A. cerana japonica, have been reported to be 
infested by $A$. woodi and to suffer colony losses due to mite infestation in winter (Singh 1957; Atwal and Sharma 1970; Atwal 1971; Maeda 2016). However, there has been no study quantifying the damage to Asian honeybee colonies by tracheal mites.

The Japanese honeybee is one of the most important pollinators in Japan; for example, it is the most dominant flower-visiting insect on common buckwheat (Taki et al. 2010). A recent nationwide survey revealed that $A$. wood $i$ is patchily distributed throughout Japan (Maeda 2016 and unpublished data). In some local regions, more than $70 \%$ of colonies are infested by tracheal mites, and such high infestation may result in regional destruction of the Japanese honeybee population (Maeda et al. 2015). To better understand the threat of acarine disease to the Japanese honeybee populations, a quantitative evaluation is necessary.

In the present study, we investigated the effects of the tracheal mite on Japanese honeybees at the colony level and the apiary level. To examine the colony-level effects, we quantified the degree of mite prevalence of Japanese honeybee colonies in autumn and then monitored the colony death over the following winter. In Japan, there is few European honeybee colony infested by $A$. woodi (Maeda 2015, 2016). In this study, therefore, we compared the results for Japanese honeybees with the findings of previous studies on European honeybees (Bailey and Lee 1959; Otis and Scottdupree 1992). For apiary-level investigation, we conducted a nationwide survey on overwinter mortality in various local regions where mite infestation and air temperature are different in cooperation with private beekeepers.

\section{MATERIALS AND METHODS}

\subsection{Mite prevalence in autumn and overwinter mortality}

The mite prevalence in 114 colonies of A. cerana japonica (percentage of bees infested within each colony) was investigated from October to December 2013 and 2014 because we observed that the mite prevalence in A. cerana japonica increased rapidly in September and the increase rate decelerated after
October (Maeda 2016). In 2013, 49 colonies were tested, and in 2014, 65 colonies were tested. All colonies had been kept in artificial beehives in randomly selected apiaries in 11 prefectures: Miyagi, Ibaraki, Chiba, Gunma, Saitama, Tokyo, Kanagawa, Nagano, Aichi, Shimane, and Hiroshima. Twenty to 30 worker bees from each colony were frozen in freezers or soaked in $70 \%$ ethanol. Detection of mite infestation was conducted by dissecting the bees under a microscope. The dissecting procedure was modified from the studies of Sammataro (2006) and Sammataro et al. (2013). The bees were dissected by pulling off the head and the first pair of legs using forceps as done by Sammataro (2006); however, we did not pull off the abdomen but kept the bee body by holding the abdomen with forceps (Maeda 2015). The mortality in each colony was monitored up to the end of the April after infestation. In the present study, a colony was defined as dead if it contained no living bees.

The relationship between mite prevalence and overwinter mortality was analyzed with logistic regression analysis. The mite prevalence and the year of the test were considered possible independent factors affecting the overwinter mortality. The analysis was conducted with JMP8.0.2 software.

To compare the winter mortality of Japanese honeybees with that of European honeybees, we used the data published by Bailey and Lee (1959) and Otis and Scottdupree (1992). Mite prevalence was measured from October to December in the present study, whereas no specific measurement period was described by Bailey and Lee (1959). Otis and Scott-dupree (1992) reported that their survey was conducted in October. The death of colonies was monitored up to the end of April for the present study and for that of Bailey and Lee (1959). Otis and Scott-dupree (1992) checked the survival of colonies from April 26 to May 5. The overwinter mortality of Japanese bee colonies was calculated for four groups that were divided according to mite prevalence, i.e., groups with $0,1-30,31-60$, and $61-100 \%$ prevalence, as in the report by Bailey and Lee (1959). The mortalities were compared between Japanese and European honeybees within each group by Fisher's exact probability test. In addition, the mite prevalence and the overwinter mortality calculated by the logistic regression equation in the present study were compared with those calculated for European honeybees (Otis and Scott-dupree 1992). 


\subsection{Mite infestation at the apiary level and overwinter mortality}

The overwinter death of 1521 colonies of A. cerana japonica kept in 227 apiaries in 33 prefectures was monitored from October 2014 to April 2015 (Figure 1). The northernmost apiary is in the city of Hachinohe, and the southernmost apiary is in the city of Minamikyusyu. The distance between these apiaries is more than $1400 \mathrm{~km}$. The average number of colonies was 6.70 \pm 0.680 (mean \pm S. E.) per apiary. The mite infestation of 129 apiaries had been investigated since April 2013. Infested colonies were detected in 83 of these 129 apiaries, and these apiaries were referred to as "infested apiaries." The other 46 apiaries had no infested colonies and thus were called "clean apiaries" (Figure 1). The 98 un-investigated apiaries were categorized into the infested area or the clean area according to the status, infested or clean, of the other apiaries in the prefecture. Thus, 77 of the un-investigated apiaries were assigned to the infested area, and the other 21 were assigned to the clean area (Figure 1).

To clarify the factors affecting the overwinter mortality of apiaries, we conducted analysis of variance (ANOVA) for colony mortalities of the investigated apiaries and for those of un-investigated apiaries. The mortalities were arcsine-root transformed to fit the assumption of homogeneity of variances. The mite infestation of the apiaries or the area and the air temperature were included as independent variables. The average of daily air temperatures from January to March for each apiary was estimated from the data by the nearest (less than $20 \mathrm{~km}$ apart) meteorological station of the Japan Meteorological Agency, Automatic Meteorological Data Acquisition System (AMeDAS) (Japan Meteorological Agency 2015). The analyses were conducted with JMP8.0.2 software.

\section{RESULTS}

\subsection{Mite prevalence in autumn and overwinter mortality}

Tracheal mites were detected in 76 of the 114 colonies in autumn. The colony mortality increased as the mite prevalence increased (Figure 2). The overwinter mortality of the intact colonies ( $0 \%$ prevalence) was $21.1 \%$. This was significantly higher than that of European honeybees $(5.5 \%$, as calculated from the data of Bailey and Lee [1959]; $P=0.0023$ by Fisher's exact probability test). When the mite prevalence was low (1-30 \%), more than half of Japanese honeybee colonies died during winter $(56.8 \%$ mortality). European honeybees, in contrast, showed significantly lower mortality (6.6\%; Bailey and Lee 1959) than Japanese honeybees ( $P<0.0001$ by Fisher's exact probability test). In the middle mite prevalence range of $31-60 \%$, significantly higher mortality $(83.3 \%)$ was recorded for Japanese honeybees than for European honeybees (38.9\%; $P=0.0256$ ). For the $61-$ $100 \%$ range of mite prevalence, Bailey and Lee (1959) divided their data at $75 \%$; however, in the present study, we had only one colony in the range of $61-75 \%$, and, thus, the $61-100 \%$ data were combined into a single category. In this highest prevalence bracket, there was no difference in the mortality between Japanese honeybees $(95.7 \%)$ and European bees $(85.7 \% ; P=0.2232)$.

Logistic regression analysis $(P<0.0001$, $R^{2}=0.3793, \chi^{2}=56.494, \mathrm{df}=3$ ) showed that the overwinter mortality was affected by the mite prevalence in autumn $\left(P<0.0001, \chi^{2}=52.4848\right)$, but not by year $\left(P>0.005, \chi^{2}=0.7911\right)$ or their interaction $\left(P>0.005, \chi^{2}=2.8083\right)$. The regression equation calculated by the logistic regression analysis was $\ln (p /[1-p])=-0.875+4.640 x$, where $p$ is the probability of mortality $(0-1)$ and $x$ is the mite prevalence $(0-1)$. The predicted probability of mortality was higher than that of European honeybees (Otis and Scott-dupree 1992) (Figure 3). When the mite prevalence was less than 0.28 , the tangent slope of mortality for Japanese honeybees was steeper than that of European honeybees (Figure 3).

\subsection{Mite infestation at the apiary level and overwinter mortality}

The estimated average daily air temperature of apiaries during winter ranged from -2.77 to $10.37{ }^{\circ} \mathrm{C}$, and the average temperature was $5.75^{\circ} \mathrm{C}$. The overwinter mortality of the infested apiaries was $51.2 \pm 4.0 \%(n=83)$, and that of clean apiaries was $28.3 \pm 5.4 \%(n=46)$ (Figure 4). Analysis of variance showed that the mite infestation had a significant effect on the 


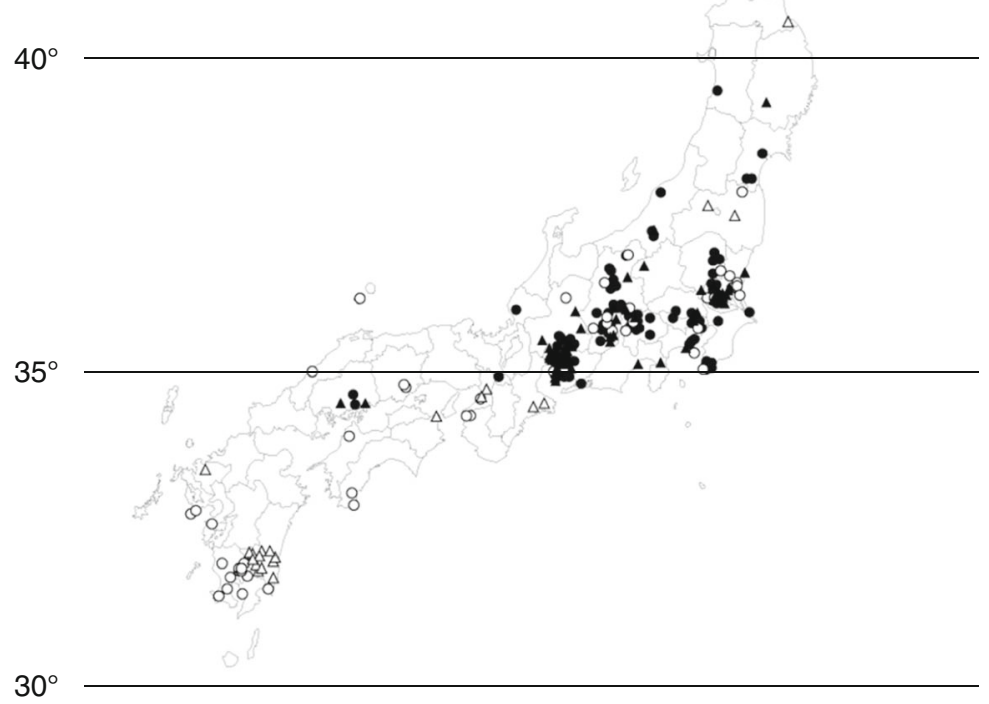

Figure 1. The location of apiaries used for the apiary level survey. Black circles indicate the infested apiaries where mite-infested colonies were found, and white circles represent the clean apiaries. Black triangles represent the apiaries in the infested area, and white triangles represent apiaries in clean areas where no mites were recorded in each prefecture.

overwinter mortality of the investigated apiaries $(P<0.001$, sum of squares $($ S.S. $)=4.0498$, $F=13.2761$, ANOVA), but not on the estimated temperature $(P>0.05$, S.S. $=0.4874, F=1.5977)$ or on the interaction between the mite infestation and the estimated temperature $(P>0.05$, S.S. $=0.1122, F=0.3679)$. For un-investigated apiaries (Figure 5), the comparison of mortality between the infested area $(55.1 \pm 4.2 \%, n=77)$ and clean area $(33.1 \pm 8.0 \%, n=21)$ showed significant difference $(P=0.0260$, S.S. $=1.5243$,
$F=5.1134$, ANOVA). The estimated air temperature and its interaction with the mite infestation did not show any significant effects $(P>0.05$, S.S. $=0.0037, F=0.0124$ and $P>0.05$, S.S. $=0.0553, F=0.1854$, respectively).

\section{DISCUSSION}

The present study clearly showed that the infestation by $A$. woodi increased the overwinter mortality in Japanese honeybee colonies. The regression 


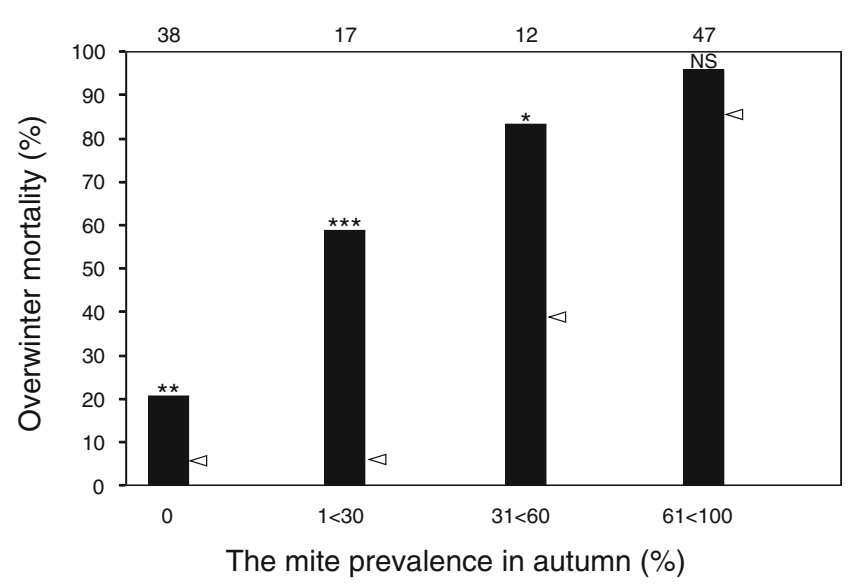

Figure 2. Overwinter mortality of Japanese honeybee colonies. The colonies were divided into four groups according to the mite prevalence: $0,1-30,31-60$, and 61-100\%. Numbers of colonies within each group are represented at the top of the graph. White arrows on the side of each bar show the results for European honeybees (Bailey and Lee 1959). Statistically significant differences between the Japanese and European honeybees are shown at the top of the bars $(* P<0.05, * * P<0.01, * * * P<0.001, N S$ not significant, Fisher's exact probability test).

equation calculated by logistic regression analysis predicted the threat conferred by mite infestation quantitatively. For example, when the mite prevalence in a bee colony exceeds $70 \%$ in autumn, it is predicted that $91.5 \%$ of colonies will die before the next spring (Figure 3). The prevalences of both Japanese honeybees and European honeybees are similarly low in summer and elevated after September (Otis et al. 1988; Dawicke et al. 1992; Maeda 2016). In the colonies where tracheal mites are present at the end of summer, the mite prevalence exceeds $70 \%$ in autumn (Maeda 2016). These results suggest that if Japanese honeybee colonies are invaded by the tracheal mites before summer, $90 \%$ of the infested colonies will not be able to survive the winter.

The estimated and observed values of overwinter mortalities for Japanese honeybees are much higher than those for European honeybees (Bailey and Lee 1959; Otis and Scott-dupree 1992; Figures 2 and 3). The mite prevalence of Japanese honeybees was investigated from October to December in the present study, versus in October only in the study of Otis and Scott-dupree (1992). Because the mite prevalence of Japanese honeybees gradually increases after October (Maeda 2016), the mite prevalence estimated for Japanese honeybees in the present study might be higher than that estimated for the month of October alone. If so, the logistic regression curve of Japanese honeybees in Figure 3 might be on the right side of the regression curve estimated based on the data for October. Namely, if the mite prevalences of all Japanese honeybee colonies were investigated in October in the same manner as done by Otis and Scott-dupree (1992), the difference between Japanese honeybees and European honeybees could be greater than that shown in the present study.

The higher mortality of Japanese honeybees could be partly explained by differences in the management of beehives between European and Japanese honeybees. In commercially managed apiaries using European honeybees, small colonies are often combined with other hives before winter, and winter feeding is applied as necessary. On the other hand, Japanese honeybees are usually not managed as well as European honeybees; for example, winter feeding is not used as frequently for Japanese honeybees as for European honeybees. In addition, small and weak colonies of Japanese honeybees tend to die during winter because it is difficult to combine colonies of Japanese honeybees. These differences might have been responsible for the higher mortality of Japanese honeybees at $0 \%$ mite prevalence.

The susceptibility of Japanese honeybees to tracheal mites seems to be higher than that of 


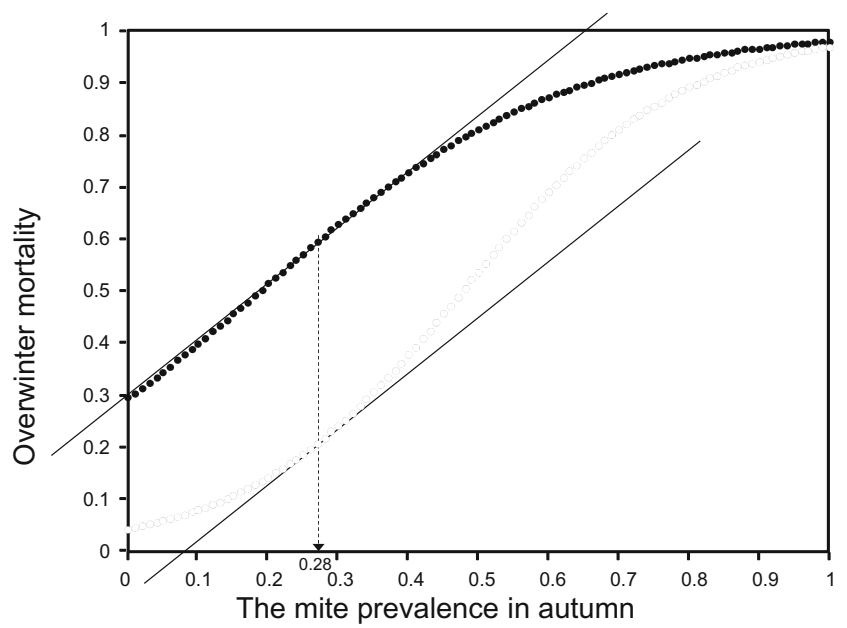

Figure 3. Results of logistic regression analysis of the mite prevalence and overwinter colony mortality. Black circles represent the predicted probability of mortality as calculated from the regression equation. White circles represent the predicted probability of mortality of European honeybees, $\ln (p /[1-p]$ ) $=-3.094+6.478 x$ (Otis and Scott-dupree 1992). (Otis and Scott-dupree [1992] reported using a value of $0.6478 x$ in this equation, but must have intended $6.478 x$.) The solid lines represent the tangent slope for each species of honeybee at 0.28 mite prevalence where the slopes are equal.

European honeybees, even when taking the higher mortality of non-infested colonies into account. As shown in Figure 2, when the mite prevalence was low, the mortality of Japanese honeybees was increased by $35.7 \%$-from 21.1 (0\% prevalence)

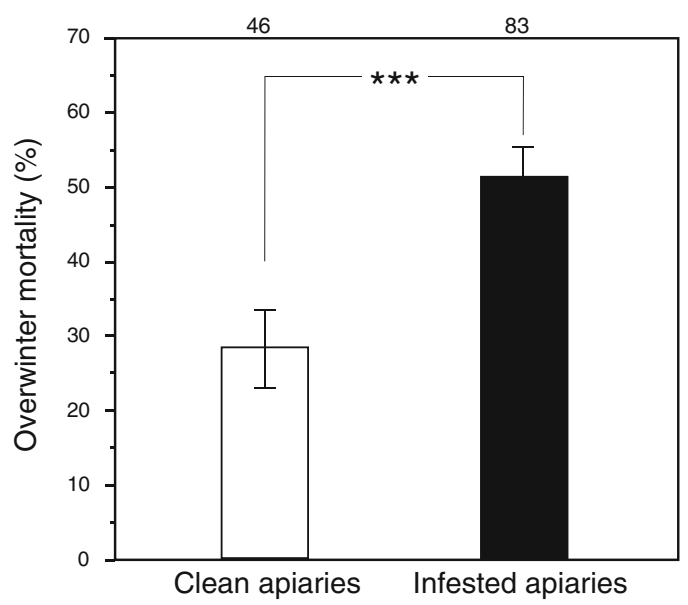

Figure 4. The overwinter mortality of the clean apiaries and the mite-infested apiaries. The difference in the average mortality between the clean apiaries (open bar) and the infested apiaries (black bar) was significant $(* * * P<0.001$, ANOVA after arcsine-root transformation). to $56.8 \%$ (1-30\% prevalence) - although the mortality of European honeybees showed only a $1.1 \%$ increase $(5.5-6.6 \%, 0 \%$ to $1-30 \%$ prevalence, respectively). Similar results were observed for the predicted mortality values: the in-

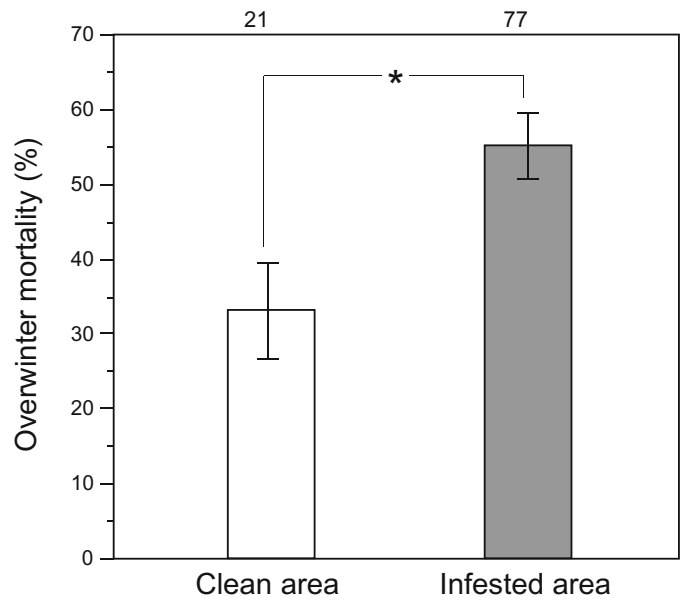

Figure 5. The overwinter mortality of the un-investigated apiaries in the clean area and in the infested area. The difference in the average apiary mortality between the clean area (open bar) and the infested area (gray bar $)$ was significant $(* P<0.05$, ANOVA after arcsineroot transformation). 
crease in mortality was more rapid when the mite prevalence was low. These results suggest that Japanese honeybees are more susceptible under a low level of mite infestation.

Downey and Winston (2001) suggested a synergistic interaction between tracheal mites and Varroa destructor on the European honeybee; colony mortality in March was much higher when bees were infested by both mites than when they were infected by a single mite. When the experiments on European honeybees were conducted (Bailey and Lee 1959; Otis and Scott-dupree 1992), there was no Varroa mite. On the other hand, Japanese honeybees in the present study could have been exposed to Varroa, and synergistic effects between the two mite species could have caused the high mortality. However, infestation by Varroa rarely occurs in Japanese honeybees, and in fact, we detected no Varroa mites in Japanese honeybees in the present study.

The colony death of European honeybees during the winter season may be due to their inability to thermoregulate, which occurs due to the reduced bee population, loose winter clusters, reduced flight muscle function, and increasing mite infestation (McMullan and Brown 2009). The high susceptibility of Japanese honeybees may be related to these factors. In addition, the colony size of Japanese honeybees is smaller than that of European honeybees. If the initial invasion and increase in mites are similar between Japanese and European honeybee colonies, the Japanese honeybee colonies might become infested more quickly due to the small colony size. To clarify the factors contributing to the high susceptibility, the development rate of the mites in Japanese honeybees and the thermoregulation ability of Japanese honeybees are under investigation.

The estimated daily air temperature of apiaries during winter did not have significant effects on the overwinter mortality of Japanese honeybees. The apiaries used in the present study are widely distributed across Japan, with the most distant apiaries being $1400 \mathrm{~km}$ apart from each other. The estimated temperatures were derived from data gathered by meteorological stations at less than $20-\mathrm{km}$ intervals. The estimated air temperature would represent the regional climate of each apiary. However, micro-conditions such as sunshine, altitude, and frost pockets may also affect the actual temperature. The relationship between the exact temperature and the overwinter mortality should be reconsidered in a further investigation.

In a previously reported study, bee mortality was always drastically increased when bees invaded a new area (Wilson et al. 1997). Following the initial epidemic, however, the mite prevalence has been shown to decrease in England (Bailey 1985; Morison et al. 1956), Greece (Bacandritsos and Saitanis 2004), and Spain (Orantes and García-Fernández 1997). A study on the relationship between mite prevalence and overwinter mortality (Otis and Scott-dupree 1992) was conducted 10 years after the first report of $A$. woodi in America (Delfinado-Baker 1984). In England, the effects of infestation on winter mortality were tested by Bailey and Lee (1959) more than 50 years after the outbreak of Isle of Wight disease (Anderson 1930). The present study was conducted only 3-4 years after the first report in Japan (Kojima et al. 2011). It is an intriguing question whether the relationship between the tracheal mites and honeybees will change over time after the first invasion of the parasitic mites into a new area and new species.

In Japan, the distribution of tracheal mites varies among regions (Maeda et al. 2015). For example, in our research from April 2013 to August 2015, we found mite-infested apiaries in 22 prefectures, but not in 13 prefectures (unpublished data). In Nagano, one of the most heavily infested prefectures, $72.5 \%$ of apiaries were infested with the mites. The present study suggested that overwinter mortality was higher in a mite-infested area than in a clean area. In the heavily infested areas, a decrease in the Japanese honeybee population due to overwinter death is a concern. The Asian honeybee A. cerana plays an important role in the pollination of various crops and natural flora and enhances the vibrancy of floral diversity and agricultural productivity (Partap 2011). Japanese honeybees also visit various plant taxa and utilize their pollen (Nagamitsu and Inoue 1999). From the viewpoint of conservation of pollinator diversity and floral diversity, it is important to clarify the impact of the tracheal mites on Asian honeybees quantitatively and to 
monitor the distribution of the tracheal mites in Asia.

\section{ACKNOWLEDGMENTS}

We wish to thank the many private apiarists throughout Japan who provided bee samplings and monitoring surveys. This work was supported (in part) by Grant for Environmental Research Projects from the Sumitomo Foundation Number 153283 and JSPS KAKENHI Grant Number 26290074.

La présence d'acariens des trachées, Acarapis woodi, provoque une forte augmentation de la mortalité hivernale dans les colonies de l'abeille japonaise, Apis cerana cerana

Acari / mort d'une colonie / période hivernale / infestation / Japon

Tracheenmilben (Acarapis woodi) erhöhen in hohem Maße die Überwinterungsverluste bei Völkern der japanischen Honigbiene, Apis cerana japonica

Asiatische Honigbienen / Tracheenmilbe / Völkerverluste / Überwinterungsverluste

\section{REFERENCES}

Anderson, J. (1930) Isle of Wight Disease in bees. I. Bee World 11, 37-42

Atwal, A.S. (1971) Acarine disease problem of the Indian honey bee, Apis indica F. Am. Bee J. 111, 134-135

Atwal, A.S., Sharma, O.P. (1970) Acarine disease of adult honeybees: prevention and control. Indian Farming 20, 39-40

Bacandritsos, N.K., Saitanis, C.J. (2004) A field study on the long-term incidence of Acarapis woodi in Greece. J. Apic. Res. 43, 21-26

Bailey, L. (1958) The epidemiology of the infestation of the honeybee, Apis mellifera L., by the mite Acarapis woodi Rennie and the mortality of infested bees. Parasitology 48, 493-506

Bailey, L. (1961) The natural incidence of Acarapis woodi (Rennie) and the winter mortality of honeybee colonies. Bee World 42, 96-100

Bailey, L. (1985) Acarapis woodi : a modern appraisal. Bee World 66, 99-104

Bailey, L., Ball, B.V. (1991) Honey bee pathology. Academic Press, San Diego
Bailey, L., Lee, D.C. (1959) The effect of infestation with Acarapis woodi (Rennie) on the mortality of honey bees. J. Insect Pathol. 1, 15-24

Borchert, A. (1940) Über die Acarapismilbe sowie Über das problem ihrer Bekämpfung. Z. F. Parasitenkunde 12, 86-93

Butler, C.G. (1945) The incidence and distribution of some diseases of the adult honeybee (Apis mellifera L.) in England and Wales. Ann. Appl. Biol. 32 , 344-351

Clark, K.J. (1991) Winter survival times of colonies infested at various levels by tracheal mites. Am. Bee J. 131, 773

Dawicke, B., Otis, G., Scott-Dupree, C., Nasr, M. (1992) Host preference of the honey bee tracheal mite (Acarapis woodi (Rennie)). Exp. Appl. Acarol. 15, 83-98

Delfinado-Baker, M. (1984) Acarapis woodi in the United States. Am. Bee J. 124, 805-806

Downey, D., Winston, M. (2001) Honey bee colony mortality and productivity with single and dual infestations of parasitic mite species. Apidologie 32, 567-575

Eischen, F.A. (1987) Overwintering performance of honey bee colonies heavily infested with Acarapis woodi (Rennie). Apidologie 18, 293-304

Eischen, F.A., Cardoso-Tamez, D., Wilson, W.T., Dietz, A. (1989) Honey production of honey bee colonies infested with Acarapis woodi (Rennie). Apidologie 20, 1-8

Furgala, B., Duff, S., Aboulfaraj, S., Ragsdale, D., Hyser, R. (1989) Some effects of the honey bee tracheal mite (Acarapis woodi Rennie) on non-migratory, wintering honey bee (Apis mellifera L.) colonies in east central Minnesota. Am Bee J 129, 195-197

Kojima, Y., Toki, T., Morimoto, T., Yoshiyama, M., Kimura, K., Kadowaki, T. (2011) Infestation of Japanese native honey bees by tracheal mite and virus from non-native European honey bees in Japan. Microb. Ecol. 62 , 895-906

Komeili, A.B., Ambrose, J.T. (1991) Electron microscope studies of the tracheae and flight muscles of noninfested, Acarapis woodi infested, and crawling honey bees (Apis mellifera). Am. Bee J. 131, 253-257

Japan Meteorological Agency (2015) Past Weather Observations. http://www.data.jma.go.jp/obd/stats/etrn/ Accessed 19 Dec 2015

Liu, T.P. (1990) Ultrastructure of the flight muscle of worker honey bees heavily infested by the tracheal mite Acarapis woodi. Apidologie 21, 537-540

Maeda, T. (2015) Infestation of honey bees by tracheal mites, Acarapis woodi, in Japan. J. Acarol. Soc. Jpn. 24(1), 9-17. In Japanese with English abstract

Maeda, T. (2016) Effects of tracheal mite infestation on Japanese honey bee, Apis cerana japonica. J. Acarol. Soc. Jpn. 25(S1):105-113

Maeda, T., Sakamoto, Y., Okabe, K., Taki, H., Yoshiyama, M., Kimura, K. (2015) Tracheal mite, Acarapis woodi (Acari: Tarsonemidae), of honey bees: biology, impact on honey bees and occurrence in Japan. Appl. Entomol. Zool. 59, 109-126. In Japanese 
McMullan, J.B., Brown, M.J. (2009) A qualitative model of mortality in honey bee (Apis mellifera) colonies infested with tracheal mites (Acarapis woodi). Exp. Appl. Acarol. 47, 225-234

Milne, P.S. (1957) Acarine disease in Apis indica. Bee World 38, 156

Morison, G.D., Jeffree, E.P., Murray, L., Allen, M.D. (1956) Acarine and nosema diseases of honeybees in Britain, 1925-47. Bull. Entomol. Res. 46, 753-759

Nagamitsu, T., Inoue, T. (1999) Differences in pollen sources of Apis cerana and Apis mellifera at a primary beech forest in central Japan. J. Apic. Res. 38, 71-78

Orantes, F.J., García-Fernández, P. (1997) A scientific note on the current low levels of honey bee tracheal mite in southern Spain. Apidologie 28, 149-150

Otis, G.W., Bath, J.B., Randall, D.L., Grant, G.M. (1988) Studies of the honey bee tracheal mite (Acarapis woodi) (Acari: Tarsonemidae) during winter. Can. J. Zool. 66, 2122-2127

Otis, G.W., Scott-dupree, C.D. (1992) Effects of Acarapis woodi on overwintered colonies of honey bees (Hymenoptera: Apidae) in New York. J. Econ. Entomol. 85, 40-46

Partap, U. (2011) The pollination role of honeybees. In: Hepburn, H.R., Radloff, S.E. (eds.) Honeybees of Asia, pp. 227-255. Springer, Berlin
Pettis, J.S., Wilson, W.T. (1996) Life history of the honey bee tracheal mite (Acari: Tarsonemidae). Ann. Entomol. Soc. Am. 89, 368-374

Phillips, E.F. (1922) The occurrence of diseases of adult bees. USDA Circ.: 218

Sammataro, D. (2006) An easy dissection technique for finding the tracheal mite, Acarapis woodi (Rennie) (Acari: Tarsonemidae), in honey bees, with video link. Int. J. Acal. 32, 339-343

Sammataro, D., De Guzman, L., George, S., Ochoa, R., Otis, G. (2013) Standard methods for tracheal mite research. J. Apic. Res. 52 : (COLOSS beebook-special issue)

Singh, S. (1957) Acarine disease in the Indian honey bee (Apis indica F.). Indian Bee J 19, 27-28

Taki, H., Okabe, K., Yamaura, Y., Matsuura, T., Sueyoshi, M., Makino, S., Maeto, K. (2010) Effects of landscape metrics on Apis and non-Apis pollinators and seed set in common buckwheat. Basic Appl. Ecol. 11, 594-602

Wilson, W.T., Pettis, J.S., Henderson, C.E., Morse, R.A. (1997) Tracheal mites. In: Morse, R.A., Flottum, K. (eds.) Honey bee pests, predators, and diseases, pp. 255-277. A. I. Root Company, Medina 